\title{
Why we should not seek individual informed consent for participation in health services research
}

\section{J Cassell, A Young}

J Med Ethics 2002;28:313-317

\author{
See end of article for \\ authors' affiliations \\ ..................... \\ Correspondence to: \\ Dr J Cassell, Wellcome \\ Health Services Research \\ Training Fellow, Department \\ of Sexually Transmitted \\ Diseases, Royal Free and \\ University College Medical \\ School, Mortimer Market \\ Centre, Off Capper St, \\ London WCIE 6AU; \\ jcassell@gum.ucl.ac.uk
}

Revised version received 16 June 2002

Accepted for publication

21 June 2002

$\Lambda$ fter a half century of rapid technological development, much organisational change in the National Health Service (NHS) is now driven by the results of medical research. Clinical medical research has traditionally been concerned with the question of whether specific therapies are effective, and usually postpones the question of how best to organise their delivery in, say, rural, or urban populations. Health services research (HSR), on the other hand, looks at the needs and outcomes of populations in relation to health care delivery, considered both as a resource issue and an organisational problem. For example, a study of the effects of screening and treating a population for the sexually transmitted infection chlamydia ${ }^{1}$ is HSR rather than clinical research. While overlapping with epidemiology, HSR is also concerned with the evaluation of new organisational structures or care pathways, which have not generally been the concern of clinical research. An example of this would be the evaluation of antenatal care by midwife teams, rather than "standard care" ${ }^{23}$ Health service research then, covers research into organisational structures or care pathways that may influence outcomes at a population level-this may include the evaluation of screening programmes, new staffing structures, resiting of services or collaborative services, to give a few examples. It does not include the use of experimental medical treatments.

The evaluation of health services through HSR requires information about the population as a whole. For example, to discover that death rates from cancer vary geographically will require access to information about patients diagnosed and their deaths, and often review of patients' NHS records. In the wake of the incorporation of the Human Rights Act into UK law, and the new Data Protection Act, there has been a rise in public concern to protect the privacy of individuals in health care law. This presents problems for the guardians and users of databases such as the cancer registries. The cancer registries have in the past collected basic personal information about individuals diagnosed, in order to enable health services and researchers to compare survival trends, as well as to detect new risks and enable their investigation. Thus death rates can be compared, ${ }^{45}$ and new risks investigated-either through statistical means or through approaching the patients concerned. ${ }^{67}$ Anonymisation of data, through destroying a code, has been suggested, in order to protect individual identities. This would make it impossible, however, to approach patients for "case control" studies, which are important in identifying new causes of cancer by comparing cases with controls, and to monitor death rates by disease. Anonymisation would also prevent the exclusion of duplicate cases, which can lead to inaccurate estimates of disease rates. It is not yet clear whether the existing registries will be permitted to record information without individual informed consent in future, though this represents a major risk to their usefulness in protecting health. ${ }^{8}$

Health services research is particularly vulnerable to the current "ethical" climate, which appears to prioritise individual consent above all other goods. We show in this paper that, in the context of a socialised health care system such as the NHS, informed consent should not always outweigh other central values in the decision making processes of ethical committees.

\section{WHY ORGANISATIONAL CHANGE IN THE NHS REQUIRES RESEARCH}

The organisation of health services has an important effect on health, which goes beyond medical treatments themselves. Even if we know, say, that improved glucose control reduces the chances of kidney damage in diabetes, this does not tell us whether monitoring at the general practitioner (GP) surgery, or the hospital will lead to the best health outcomes overall-or who is likely to be worse off in each setting. In effect, managerial and organisational decisions are often community level health interventions. This fact has been recognised in the reorganisation of UK cancer services to ensure universal access to specialist advice, ${ }^{9}$ which seeks to redress postcode inequalities, and social inequalities in outcomes. It makes no sense to evaluate such changes at the level of individual patients only, by recruiting individually 
patients who agree to participate in data collection. The proper way to evaluate such changes is by looking at the whole population involved, including a careful search for disadvantaged populations in each setting who may find the service less usable or less effective. The delayed cluster randomised trial-in which a planned change is introduced first in randomly selected areas, then to all areas-is the optimal way to evaluate such changes. In practice, however, this is rarely done.

It is essential that organisational changes are evaluatedotherwise we may delude ourselves about what the features of an effective service are, and create new forms of inequality. For example, there is currently concern that this may happen with the inadequately evaluated crisis resolution team in psychiatry, which is now part of the NHS plan. ${ }^{10-12}$ Organisational change is, however, lightly regulated, in that it has traditionally been possible to introduce major changes without preceding research, or even rigorous monitoring of the effects of their implementation.

Similarly, there is currently serious concern in genitourinary medicine (GUM) and sexual health clinics, that demand has markedly exceeded capacity. As a response, in a service that has traditionally prided itself as offering walk-in, open access services, many clinics have become appointment only. ${ }^{13}$ Such a change in access policy is likely to have a major impact on the proportion of symptomatic patients who access services before their symptoms disappear (though they may remain infectious). Yet the change to appointments has not been properly evaluated, and we do not know the optimal way to streamline workload while maximising our capacity to see those with acute infectious sexually transmitted diseases (STDs). Such work urgently needs to be done, but since it requires knowledge about the patients who don't make it through barriers to services, it is particularly difficult to undertake once new patterns of access are established.

\section{THE HISTORY OF INFORMED CONSENT, AND THE VERY IDEA OF INDIVIDUAL AUTONOMY IN HSR}

Informed consent emerged in the 1980s and 1990s as the ethical touchstone of medical research, and is now enshrined in practice and a range of international guidelines as one of the main preconditions of medical research. Our current emphasis on the rights of individuals to knowledge and control over their participation in medical experimentation emerged some two years after the second world war with the Nuremberg code. ${ }^{14}$ Recognition that doctors had collaborated in dangerous and lethal experiments gave rise to a felt need for a legal and ethical framework which might prevent further atrocities. It was not until some 15 years later, however, that a modified version of the Nuremberg code was adopted by the World Medical Association, which later became the Declaration of Helsinki. ${ }^{15}$ Even so it was many years before the strenuous efforts of Pappworth and Beecher, who exposed shocking examples of experimental malpractice in the liberal democracies of the USA and Great Britain, that a sustained critique replaced benevolent paternalism with the now accepted general requirement that patients must be fully informed of, and agree without coercion to, any participation in medical research. ${ }^{16}$ Nowadays, disagreements centre on whether health service inequality between countries should influence the medical research and consent processes, ${ }^{17-19}$ what exceptions there should be to the need for informed consent, $^{20}$ and whether journals should publish research without consent. ${ }^{21}$ Exceptions to the need for informed consent are generally agreed to be very few, and require that there be negligible danger to the individuals concerned-for example, unlinked anonymous HIV testing where there is no possible tracing of samples to individuals has recently been allowed in the UK, and even here individuals may opt out.
The Helsinki declaration is the explicit standard under which ethics committees evaluate medical research, and lays heavy emphasis on the need for informed consent. Unfortunately, it does not provide useful guidance on the issue of consent for HSR, since its approach presupposes that ethics committees are considering traditional medical research-the effects of individual level interventions on individual patients. As we will show, it is incoherent in relation to HSR which deals with organisational change.

The Helsinki declaration ${ }^{15}$ divides research into two kindstherapeutic and non-therapeutic. This widely accepted distinction fits a picture according to which research is carried out on individuals, and in which the brave, the altruistic or the foolhardy who take part in, say, physiological experiments for no possible benefit (non-therapeutic research) deserve special protection. This is why, in general, consent for therapeutic trials may be given at a younger age than for non-therapeutic trials. According to the declaration: "subjects must be volunteers and informed participants in the research project", and "each potential subject must be adequately informed of the aims, methods, sources of funding, any possible conflicts of interest, institutional affiliations of the researcher, the anticipated benefits and potential risks of the study and the discomfort it may entail. The subject should be informed of the right to abstain from participation in the study" [our emphasis].

The Helsinki declaration thus describes medical research in relation to individual human subjects and prescribes safeguards designed to protect the individual-his or her right to refuse must be protected by the social structures which monitor and enable medical research. The interventions used in medical research are therefore, on the Helsinki model, presumed to be interventions that an individual could meaningfully refuse. By this we mean that, should the experimental intervention prove to be the better treatment, it is something that a patient could effectively decline to be treated with. It is a procedure or substance that can be administered on an individual basis, to individual people.

The model of medical research implied by the Helsinki declaration prompts us to ask what it would mean for an individual to decline a model of service provision. This is an important issue in any community with a universal health service. Consider the example of midwifery care. This has been organised in a number of ways, including "team" midwifery in which mothers receive all care from a small team of known midwives, and "split provision" in which antenatal and postnatal care is provided by a different set of midwives from those on the labour ward. It is indisputably important to evaluate the merits of each-in terms of "objective" outcomes, as well as the preferences and experience of patients and staff. This is done through HSR. ${ }^{2} 3$

The Helsinki model of consent, which requires that individuals can opt out of the research process and the treatment, is, however, poorly adapted to guide us on consent for this kind of research. The are two crucial areas of mismatch between the Helsinki model of research, and such examples of HSR in disguise which take place without widespread scrutiny:

1. Women cannot opt out of the model of service provision during the research period. Models under evaluation are usually termed "pilots" to deflect critical attention from what is in effect compulsory participation in research. Individual patients cannot effectively refuse to take part in the research.

2. Women will not be able to opt out of the intervention-for example, team midwifery, if it becomes the standard local model of care. Thus patients are not in a position to refuse the intervention itself, if it is successful.

Consequently, research into such models of service provision, even where they go through ethics committees, cannot meet the requirements of the Helsinki Declaration and the public is misled if they are claimed to do so. 


\section{ETHICS COMMITTEES AND THE DOUBLE STANDARD BETWEEN RESEARCH AND ORDINARY PRACTICE}

One might wonder whether organisational research is really patient research at all. As we have argued above, the specific protections appropriate to patient research do not apply coherently to these cases. It is unlikely that the authors of the original Helsinki Declaration envisaged that it would be used to legitimate or reject research into the organisation structures and operation of complex large health services in this way. As a consequence, we would expect to find ethics committees uncomfortable with their role in evaluating such research, and that they might on occasion decline to oversee it. Health service researchers commonly report, however, that ethics committees refuse to approve studies designed to evaluate competing service models on the grounds that individual consent is not sought. This represents the evasion of an uncomfortable problem on the part of ethics committees. The Helsinki declaration, which guides ethical review, does not adequately cover these cases, and an alternative source of guidance needs to be found. Yet organisational changes are constantly taking place, often unevaluated and unreported, and do not reach ethical review. What ethics committees should be doing, if they take the Helsinki declaration seriously, is objecting vociferously not just to the studies, but to the fact that unevaluated organisational changes are taking place, which place patients at risk, and drawing attention to the fact that we do not at present have a sensible way of sorting these issues out.

Ian Chalmers has made a similar point in relation to clinical medical research, ${ }^{22}$ criticising bioethicists for wilfully neglecting the consequences of a widespread, but unacceptable, double standard for consent. Whilst in clinical research a detailed, accurate description of likely outcomes must be put before the patient before he or she consents to the research, no such requirement operates in routine practice. It is still considered normal for patients to consent to routine treatments without anything like the same amount of information-and indeed this information may not be known, or even in the process of being gathered. Chalmers et al consider this a scandal-particularly since there is empirical evidence in the case of many diseases that patients who are treated under research protocols do better than those who are not. The reasons for this are unclear-the improved outcomes may be due to some combination of selection bias, the following of protocols as such, or the frequency of follow up. They point out that the fact of better outcomes across the board in research is not widely known, and appears indeed to be suppressed by ethical "experts".

Chalmers's argument has important implications for health service research, as well as for consent by individuals to treatment. It is likely that outcomes are generally better in services subject to ongoing research into the effects of the systematic features of health care, as they are in clinical trials. While community health councils and other bodies are consulted on "major" issues likely to provoke popular outcry or lose parliamentary seats, there is no process of consultation for organisational changes in general. Yet these are not subject to the rigours of clinical trials, and are generally poorly evaluated. They may even pass unnoticed by the public at large.

\section{SO HOW CAN WE LEGITIMATE HSR AND ORGANISATIONAL CHANGE IN THE NHS?}

The NHS has a special and privileged place in the state-until recently, crown immunity even protected its cockroaches from public humiliation. Surveys continue to show overwhelming support for its guiding principles of free care at the point of need, equality of care and access, and universal provision.

What is the nature of this unique institution in our community, and what is our relation to it? Its status is in some respects rather like what the political philosopher Jean Bodin termed a cité-a grouping within a state which may have privileges or immunities, and (importantly here) enforce its own rules for certain purposes..$^{24}$ Clearly the NHS, in consultation with government, does enforce its own rules in relation to the organisation and functioning of services, and access of patients to those services. The NHS has a position that is both privileged (its decisions affect us all), and constantly under scrutiny (in the form of its elected political masters, and local or national pressure groups).

In the respects suggested above, the NHS resembles Bodin's cité, and we as UK citizens are its members. Now whilst membership of the NHS is clearly not the same as a citizen's membership of the state, it shares with citizenship the fact that it carries certain universal and equal rights. Protecting such rights is part of the purpose of the Human Rights Act and other legislation. What these rights are has important implications for our relationship to the NHS. This membership is usually unnoticed, but sometimes comes to the fore either through illness, or through acting in a representative capacity-for example, through belonging to a pressure group lobbying the health authority. In what way, then, does our membership of, and political endorsement of, the NHS carry with it a commitment to its ideals of equality and universality?

With certain aspects of Bodin's model of a cité in mind, we can now give an account of what the status of the NHS in society means for organisational change and HSR in the contemporary context of the NHS.

\section{THE NHS AND THE RIGHT NOT TO BE EXPLOITED}

A key consideration in this picture of the NHS is that we are members, rather than consumers or patients. In the light of this, we can develop a conception of the obligations of the NHS, relevant and peculiar to this membership. Various duties of the NHS emerge, particularly from the claim that we have equal membership of it. The most germane of these is the obligation of all institutions-set out in article 14 of the European Convention on Human Rights, incorporated into UK law through the Human Rights Act- to avoid discrimination. ${ }^{25}$ Discrimination on the basis of sex, race, and importantly, social origin or property or "other status" by public bodies is specifically outlawed, and they have a duty to promote non-discrimination.

If, broadly following Bodin's conception of the cité, we consider ourselves as members of the NHS, we are all bound by the articles of the Human Rights convention and other legislation which regulate it as a public body. By this we mean that our NHS rights as individuals are subject to the need to protect the rights of all members. In this case, the community is the NHS-individual members do not have a right to benefit from the fact of institutional discrimination within it. If HSR-in the form of organisational research and public health surveillance-is essential in ensuring that the most effectively organised services are provided for all, what does this mean for consent to HSR?

Following from the requirement for equal and universal membership of the NHS as a version of the cité, it can be assumed for each individual member of the NHS that:

1. He or she has a duty to act in a way such as to minimise systematic inequality within the NHS.

2. He or she has a duty to cooperate with making the NHS equally available to all other members.

Mary Warnock argues that ultimately what we, as individuals and society, demand from the research process is that it should not exploit us. ${ }^{26}$ This, she believes, is a more useful guiding principle than a blanket demand for consent. While not uncontroversial, ${ }^{27}$ this may be a useful approach for HSR, given the difficulties in bringing the Helsinki Declaration to bear on it. 
The evaluation of organisational change through HSR requires the overwhelming, or universal, participation of patients using a service, at least for data collection, if it is to provide valid information. Yet participants in research, when consent is sought, are a limited subset of the potential population who will eventually be affected by service changes-and they are likely to be a relatively privileged subset. It is inevitable that barriers of literacy, the fear of authorities, cost of travel, poorer health, and less secure jobs of the underprivileged, will be real barriers to participation. The demands of the research situation on the patient include time for the consent process, high literacy levels to read much patient information, and a frequently increased number of follow ups ${ }^{22}$-these almost certainly are genuine barriers to participation, though there is little evidence on the extent of their effect. Where HSR contributes to the planning of services and policy making, the voice of the socially excluded may be muffled, and that of the better educated and materially secure, artificially amplified.

If ethics committees require the signing of complex consent forms and the reading of information sheets (often in themselves a disincentive to come back) in order to collect basic outcomes information in HSR, we risk discriminating against the most vulnerable-by accepting a status quo which makes their generally poor outcomes and access less visible. This is incompatible with the ambition of the NHS to equalise opportunities for health. A right to individual informed consent, interpreted as an absolute requirement in all areas of research, militates against health care for disadvantaged minorities, since some groups will have the notional "right" to health care but are not in a position to exert that right equally.

The requirement that patients give individual informed consent to organisational research, as a result of an ethical review framework designed for individual clinical research, is misleading and inappropriate. It gives a false legitimacy to "successful" pilot services which may have been tested only on a small, unrepresentative sample of the population which will be affected. At the same time it disguises the fact that decisions taken on the basis of such research will be compulsory for the patients affected. For example, if diabetic care is moved to GP surgeries, patients will not be able to opt to attend hospital outpatients. We have argued that at present inappropriate overregulation of research, along with unchecked managerial experimentation, militate against the effective evaluation of health services.

\section{SOME OBJECTIONS CONSIDERED}

A clinical director might reasonably object to the implications of these points. Surely organisational change should not be subject to the same constraints as research? After all, one cannot spend the whole NHS budget on randomised trials, nor can we stand still waiting for the results to come in. And we cannot run a major consultation each time we want to reorganise the appointments system for the diabetic clinic.

This is absolutely right, and is a reason why we should resist assimilating HSR to the paradigm of clinical research, in accordance with the current practice of ethics committees. Health service research generally deals with historical processes, often driven by the results of clinical research though often by wider political or policy determinants. It is clearly legitimate for the NHS to be seeking to widen the benefits of technological advances, such as (say) urinary screening tests for chlamydia infection.

We should regard HSR not as an analogue of clinical research, but rather as an operational requirement of the NHS, which is needed in order to ensure that its fundamental ideals are fulfilled. Avoidance of a repeat "Bristol" scandal, in which high death rates in paediatric heart surgery at a single hospital were allowed to continue unchecked, requires ongoing, properly regulated sharing of suitably confidential or anonymised information. This is a basic requirement for picking up organisational problems that can damage patients at an early stage.
HOW SHOULD WE SEEK CONSENT FOR HSR THEN? IT CAN'T BE LEFT TO THE DOCTORS

If individual informed consent is not the right approach to enabling the activities of HSR, what should the NHS be doing to avoid coercing individuals and populations to use services that do not work, which they do not like, or which significantly disadvantage the health of vulnerable groups. The NHS needs to think seriously about how to seek consent, on an ongoing basis, from its users for organisational research and for public health surveillance, which jointly allow monitoring of its achievements and failures.

Consultation with representative groups, such as focus groups, citizens' juries, surveys, and qualitative interviews with service users-and, importantly, non-users-may be appropriate, depending on the scale and nature of the change envisaged. Whereas individual consultation is necessary at the level of treatments, consultation with diverse members of the community is the only way of gaining endorsement for organisational changes or public health surveillance. It is particularly important to find new ways of listening and responding to the views of the vulnerable groups who may find it difficult to attend meetings, and are not typical of existing patient representatives.

Nevertheless, consultation alone is not enough to ensure the quality and accessibility of services. It is often necessary to enter on an organisational change, and research its effects, with a particular view to effects on excluded groups. Research into the reasons for lower breast cancer survival in socioeconomically disadvantaged communities is a good example of this. It requires identification of cases through the cancer registry, then death register and NHS record review. ${ }^{28}$ This should be done without seeking individual informed consent for data collection-though of course patients must be made aware, through leaflets and explanation, that data collection for this purpose takes place. And when they are being monitored and cared for in an experimental service, they must be told about this and invited to comment on it. Patients, and the public at large, must be informed of the ongoing public health surveillance systems, their purposes, their methods for protecting identity, and their successes or failures. At present, these are largely unknown by the public at large, and this has contributed to the current climate of fear and suspicion in which restrictive interpretation of data protection legislation threatens their continuing existence. ${ }^{8}$

If we are serious about seeing the effects of service change on vulnerable groups, then rather than treating HSR with suspicion, we should consider forcing research methodologies into the domain of management. For example, where a new service is piloted, it is only too tempting to do it in the most propitious setting, perhaps a well staffed purpose built surgery, with affluent English speaking patients, and a bus stop outside, then congratulate oneself afterwards on its success. Instead, it should be compulsory to randomise among possible sites, enough of them to give a spread of experiences, so as to evaluate a new service in difficult settings, and minimise the risk of importing a service unsuitable for a local population. The delayed randomised trial, rather than the pilot project which ran out of steam, should be the norm for managerial change. This will need more collaboration between trusts and health authorities than is usual for managerial changes-and should break down the traditional barriers between research and everyday management in the NHS.

\section{CONCLUSIONS}

Service providers and ethics committees have evaded important social and ethical questions about the place of HSR in the NHS. This has allowed organisational change in the NHS to remain unregulated and largely unevaluated. Given the special status of the NHS in the UK, we need to reconsider our relation to HSR, and look critically at how informed consent is 
dealt with by ethics committees. In particular, we must avoid its use as a shibboleth which gives unquestioned priority over all other duties and values. In assimilating the question of consent in HSR to that of consent in clinical research, while avoiding the difficulties in fitting it to the traditional model of consent, ethics committees have done the public a disservice by avoiding the wider issue of social exclusion as a core concern of the NHS.

\section{FUNDING}

Dr Jackie Cassell's salary is paid by the Wellcome Trust.

\section{CONFLICT OF INTEREST}

Dr Jackie Cassell works in Health Services Research.

\section{ACKNOWLEDGEMENTS}

We are grateful to Peter Trail, John Imrie, Professor Anne Johnson, and Professor Ian Weller, for comments on an earlier draft of this paper.

\section{Authors' affiliations}

J Cassell, Department of Sexually Transmitted Diseases, Royal Free and University College Medical School, London, UK

A Young, School of Social Sciences, University of Sussex, Brighton, UK

\section{REFERENCES}

1 Scholes D, Stergachis A, Heidrich FE, et al. Prevention of pelvic inflammatory disease by screening for cervical chlamydial infection. New England Journal of Medicine 1996;334:1362-6.

2 Biro M, Lumley J. The safety of team midwifery: the first decade of the Monash Birth Centre. Medical Journal of Australia 1991;155:478-80.

3 McLachlan $\mathbf{H}$, Forster D, Brennecke $\mathrm{S}$, et al. Team midwife care: maternal and infant outcomes. Australian \& New Zealand Journal of Obstetrics \& Gynaecology 2001;41:257-64.

4 Gatta G, Capocaccia R, Sant M, et al. Understanding variations in survival for colorectal cancer in Europe: a EUROCARE high resolution study. Gut 2000;47:533-8.

5 Gatta G, Capocaccia R, Coleman MP, et al. Toward a comparison of survival in American and European cancer patients. Cancer 2000;89:893-900

6 Roman E, Doyle P, Maconochie N, et al. Cancer in children of nuclear industry employees: report on children aged under 25 years from nuclear industry family study. British Medical Journal 1999;318:1443-50.

7 Bithell JF, Dutton SJ, Draper GJ, et al. Distribution of childhood leukaemias and non-Hodgkin's lymphomas near nuclear installations in England and Wales. British Medical Journal 1994;309:501-5.
8 Verity C, Nicoll A, Manning D. Education and debate: consent confidentiality, and the threat to public health surveillance. British Medical Journal 2002;324:1210-13.

9 Calman KC, Hine D. Expert Advisory Group on Cancer Services. A policy framework for commissioning cancer services: a report to the chief medical officers of England and Wales. London: Department of Health and the Welsh Office, 1995.

10 Burns T. Psychiatric home treatment. Vigorous, well designed trials are needed. British Medical Journal 2000;321:177.

11 Pelosi AJ, Jackson GA. Home treatment-enigmas and fantasies. British Medical Journal 2000;320:308-9.

12 Smyth MG, Hoult J. The home treatment enigma. British Medical Journal 2000;320:305-8.

13 Diuretic T, Catchpole M, Bingham J, et al. Genitourinary medicine services in the United Kingdom are failing to meet current demand. International Journal of STD and AIDS 2001;12:571-2.

14 The Nuremberg Code (1947). British Medical Journal 1996;313:1448

15 World Medical Association. Declaration of Helsinki. Adopted by the 52nd World Medical Association General Assembly, Edinburgh, Scotland, October 2000

16 Pappworth MH. Human guinea pigs: experimentation on man. London: Routledge, 1967.

17 Barry M. Ethical considerations of human investigations in developing countries: the AIDS dilemma. New England Journal of Medicine 1988:319:1083-6.

18 Omene JA, Lurie P, Wolfe SM, et al. Science, ethics, and future of research into maternal-infant transmission of HIV-1. Lance 1999;353:1878-81.

19 Wilfert CM, Ammann A, Bayer R, et al. Science, ethics, and the future of research into maternal infant transmission of HIV-1. Lancet 1999:353:832-5.

20 Doyal L. Journals should not publish research to which patients have not given fully informed consent-with three exceptions. British Medical Journal 1997;314:1107-11

21 Smith R. The importance of patients' consent for publication. British Medical Journal 1996:313:16.

22 Chalmers I, Lindley RI. Double standards in informed consent. In: Doyal L, Tobias JS, eds. Informed consent in medical research. London: BMJ Books, 2001: 266-75.

23 Oxman AD, Chalmers I, Sackett DL. A practical guide to informed consent to treatment. British Medical Journal 2001;323:1464-6.

24 Sabine GH. A history of political theory [3rd ed]. London: Harrap, 1963: 405

25 Human Rights Act 1998. London: The Stationery Office, 1998.

26 Warnock M. Informed consent-a publisher's duty. In: Doyal L, Tobias JS, eds. Informed consent in medical research. London: BM Books, 2001: 129-30

27 Doyal L. The moral importance of informed consent in medical research: concluding reflections. In: Doyal L, Tobias JS, eds. Informed consent in medical research. London: BMJ Books, 2001: 312-13.

28 Macleod U, Ross S, Twelves C, et al. Primary and secondary care management of women with early breast cancer from affluent and deprived areas: retrospective review of hospital and general practice records. British Medical Journal 2000;320:1442-5. 